\title{
Mengukur Efektivitas Penggunaan Sepeda Kampus ITS Menggunakan Metode KJ Technique
}

\author{
Putri Dwitasari, Nurina Orta Darmawati, Alifia Diaulhaqiqi, Karina Sheila Azura, Alitsya Ilma \\ Ramadhani, dan Ananda Putri Wulansari \\ Departemen Desain Komunikasi Visual, Fakultas Arsitektur Desain dan Perencanaan, \\ Institut Teknologi Sepuluh Nopember, Surabaya, Indonesia \\ e-mail: dwitasariputri@gmail.com
}

\begin{abstract}
Abstrak-Sepeda kampus ITS merupakan fasilitas yang mendukung program Eco Campus ITS, namun tidak banyak warga ITS terutama mahasiswa yang memanfaatkan fasilitas sepeda kampus ini. Mereka lebih memilih menggunakan kendaraan bermotor untuk mobilitas di lingkungan kampus. Tujuan dari riset ini adalah mencari jawaban atas permasalahan mengapa tidak banyak warga ITS yang menggunakan fasilitas sepeda kampus ITS. Metode yang digunakan adalah $K J$ Technique untuk mengukur efektivitas penggunaan sepeda kampus. Hasil riset menggunakan $K J$ Technique ini diharapkan dapat digunakan sebagai rujukan untuk mengatasi masalah bagi pengembangan sepeda kampus ITS kedepannya, sehingga mahasiswa dapat ikut berpartisipasi dalam menjal ankan program Eco Campus ITS.
\end{abstract}

Kata kunci- Sepeda kampus ITS, efektifitas, KJ Technique,

Abstract-Campus bicycles are facilities that support the Eco Campus program, but not many of ITS residents, especially students who take advantage of this campus bicycle facilities. Thev prefer to use motorized vehicles for mobilitv on cambus. The purpose of this research is to find answers to the problems why not many ITS residents use ITS campus bicycle facilities. The method used is KJ Technique to measure the effectiveness of campus bicycles. The results of the research using $\mathrm{KJ}$ Technique are expected to be used as a reference to overcome problems for the development of ITS campus bikes in the future, so that students can participate in running the ITS Eco Campus program.

Keywords- ITS campus bicycle, effectiveness, KJ Technique, eco campus

\section{PENDAHULUAN}

Sepeda kampus ITS merupakan salah satu fasilitas yang disediakan oleh kampus dimana seluruh warga ITS yang terdiri dari mahasiswa, dosen serta pegawai di lingkungan kampus ITS yang telah terdaftar menjadi anggota sepeda kampus dapat meminjamnya secara gratis. Fasilitas ini termasuk dalam salah satu program kampus, yakni program Eco Campus untuk menumbuhkan budaya bersepeda dan mengurangi dampak polusi udara akibat kendaraan bermotor di lingkungan kampus ITS. Sepeda kampus ini nantinya hanya digunakan pada jalur (track) sepeda yang telah disediakan di lingkungan kampus ITS, satu sepeda untuk satu pengendara, terdapat tempat penyimpanan tas yang maksimal kapasitasnya disarankan $10 \mathrm{~kg}$ dan bukan untuk penumpang. Selama sepeda belum dikembalikan kepada petugas, maka sepeda menjadi tanggungjawab penuh dari peminjam baik mahas iswa, dosen, dan karyawan. Termasuk juga untuk masalah kehilangan [1].

Pada awalnya, cara mendaftar dapat dilakukan dengan mengunduh formulir di website ITS yakni its.ac.id dan setelah diisi dapat di berikan kepada Pusat Inkubator Industri (BKIBV) ITS dengan membawa fotocopy KTP, KTM , pas foto $3 \times 4$ berwarna sebanyak 2 lembar serta menandatangani formulir tersebut [2]. Namun sekarang tata cara peminjaman lebih mudah dengan hanya mendatangi shelter point sepeda kampus dan mengisi administrasi serta meninggalkan KTP, warga ITS sudah dapat meminjam fasilitas ini. Dengan kemudahan ini diharapkan lebih banyak lagi warga ITS terutama mahasiswa memanfaatkan fasilitas sepeda kampus untuk mempermudah mobilitas di area kampus ITS.

Terdapat lebih dari lima ratus unit sepeda yang tersebar di 3 titik kampus atau shelter point yakni di gerbang utama ITS, area asrama mahasiswa serta di depan gedung riset Molina. Gambar 1 menunjukkan unit sepeda kampus yang telah di cek kondisinya dan siap untuk disewakan.

Penempatan shelter point dapat dilihat pada Gambar-gambar 2, 3 dan 4. Sebelum siap untuk disewa, pegawai shelter akan memeriksa terlebih dahulu kondisi kelayakan sepeda.
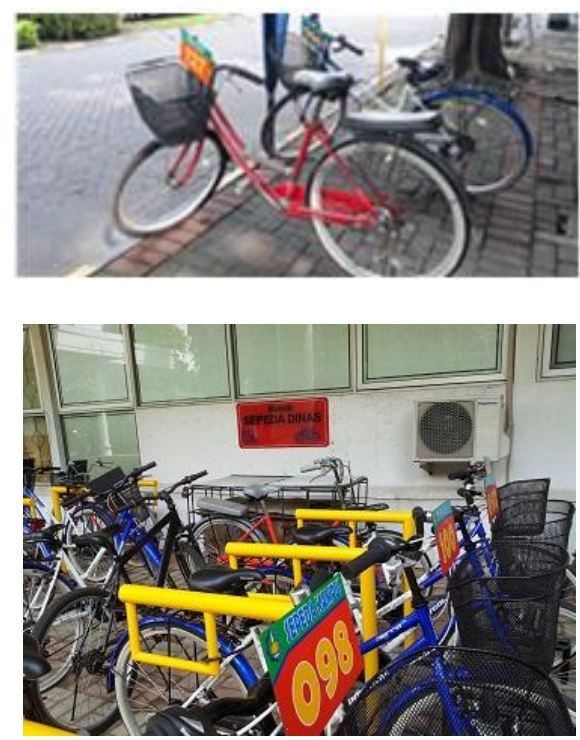

Gambar 1. Unit sepeda kampus IT S 


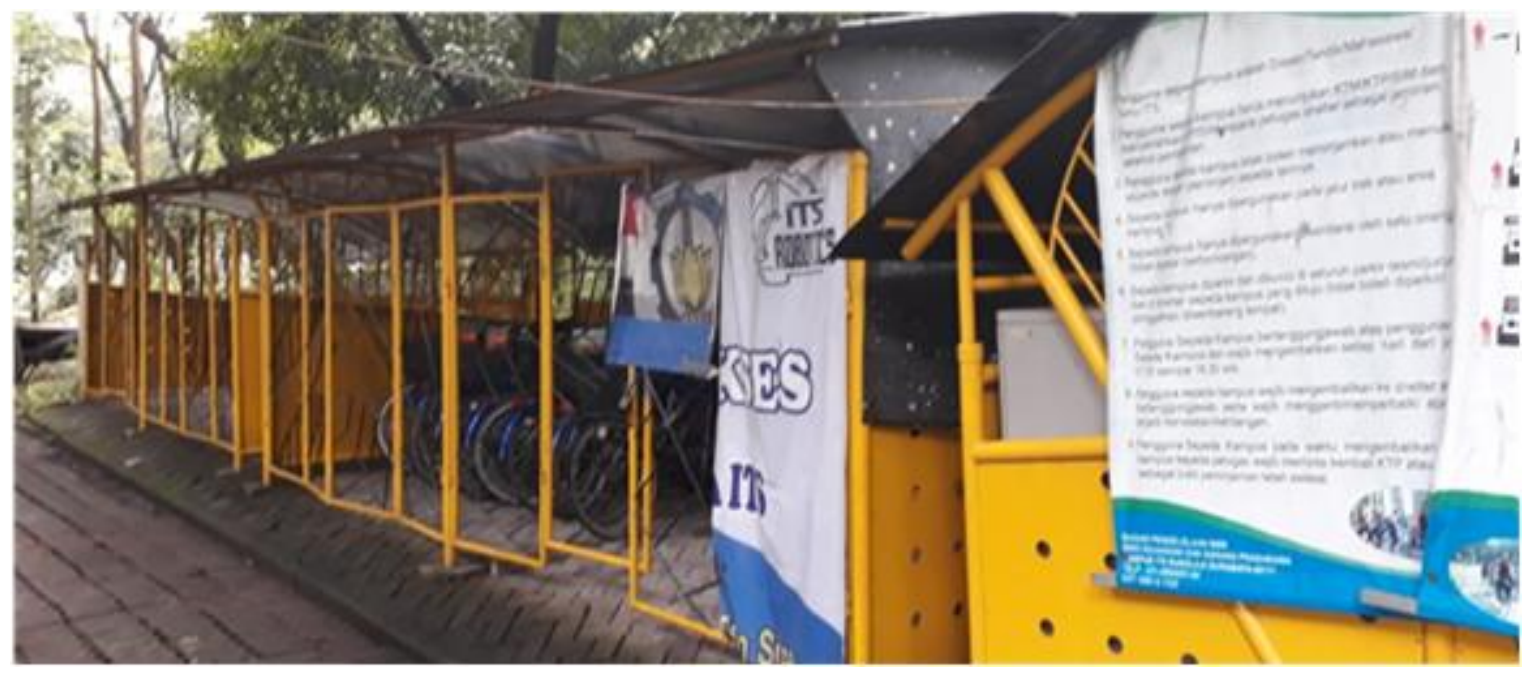

Gambar 2. Shelter Point sepeda kampus IT S di pintu masuk utama Gerbang IT S.

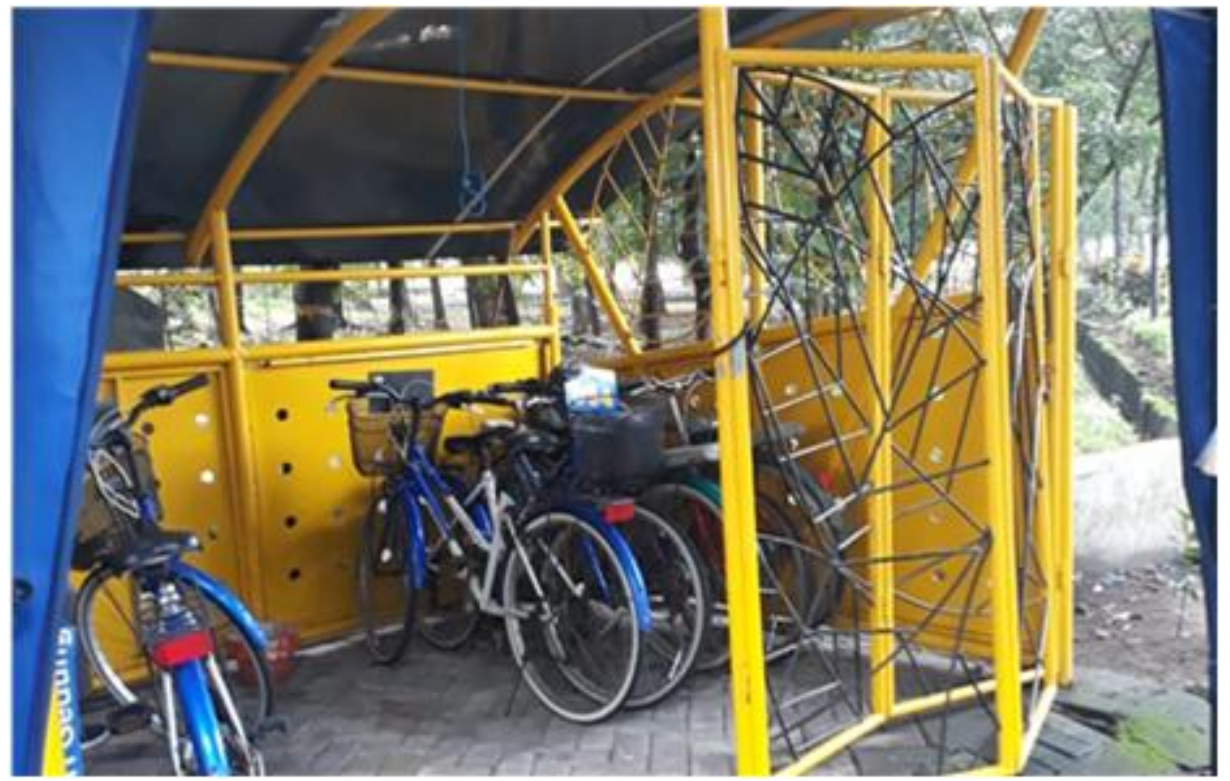

Gambar 3. Unit sepeda yang berada di Shelter Point sepeda kampus IT S di pintu masuk utama Gerbang ITS

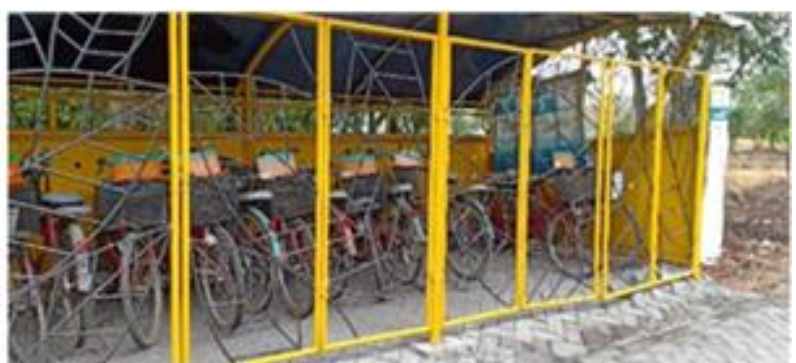

Gambar 4. Shelter Point sepeda kampus IT S di Area Asrama Mahasiswa

Menurut Bapak Yus selaku petugas Shelter Point peminjaman sepeda kampus ITS menyatakan bahwa sepeda kampus dapat dibawa selama maksimal 6 hari dengan catatan peminjam harus memperbaharui data sedikitnya 3 kali selama 6 hari peminjaman tersebut (Gambar 5). Waktu peminjaman sepeda kampus sendiri dibatasi oleh pihak kampus dari pukul 6 pagi hingga 5 sore untuk meminimalisir terjadinya pencurian sepeda.

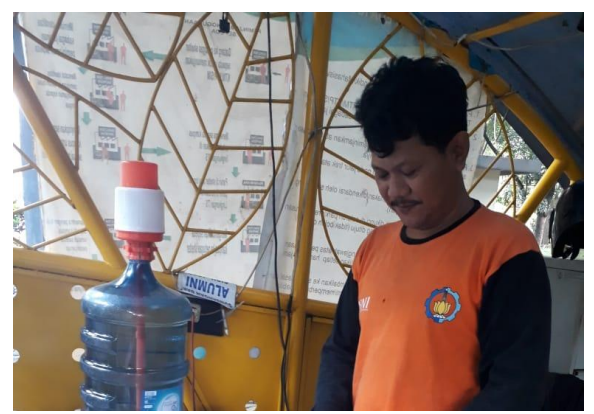

Gambar 5. Wawancara dengan Bapak Yus Selaku petugas Shelter Point Peminjaman sepeda ITS.

Bapak Yus selaku petugas shelter Point selalu secara berkala memeriksa buku peminjaman sepeda untuk mengetahui jumlah unit sepeda yang disewa pada hari tersebut. Dari hasil wawancara yang dilakukan terhadap petugas shelter point kemudahan cara peminjaman masih kurang menarik minat warga ITS untuk menggunakan fasilitas ini. Sepeda kampus hanya diminati oleh mahasiswa 
yang berasal dari luar kota dan tidak memiliki fasilitas kendaraan untuk mobilitas dilingkungan kampus. Selain itu, yang biasa menyewa sepeda kampus adalah mahas is wa dari luar negeri namun dengan tata cara khusus melalui koordinasi International Office (IO). Dari ratusan sepeda yang terdapat di shelter point, dalam sehari hanya 20 sepeda yang keluar. Padahal banyak keuntungan yang ditawarkan, antara lain segala kerusakan akan ditangani oleh petugas shelter, sepeda boleh keluar dari lingkungan kampus pada batas waktu yang telah ditentukan, waktu pengembalian diperpanjang sampai pukul 5 sore. Namun hal tersebut masih kurang menarik minat warga ITS karena beberapa alasan antara lain adalah cuaca panas, kurang praktis, kurang efektif, jumlah shelter kurang menyebar, cara peminjaman yang rumit, dan tidak tau prosedur peminjaman. Buku peminjaman serta data peminjam dapat dilihat pada Gambar-gambar 6 dan 7 .

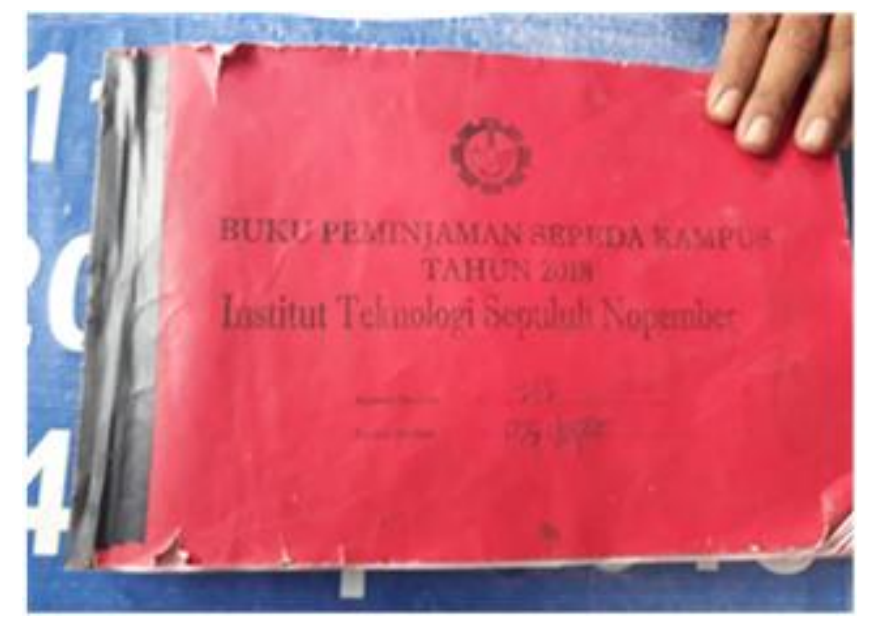

Gambar 6. Buku peminjaman sepeda kampus IT S

Dari hasil wawancara serta observasi di lapangan, diperlukan sebuah pengukur efektifitas penggunann fasilitas sepeda Kampus ITS agar nantinya dapat digunakan sebagai rujukan untuk mengatasi masalah kurangnya minat warga ITS terutama mahasiswa untuk memanfaatkan fasilitas sepeda kampus.

\section{METODE}

Metode yang digunakan untuk permasalahan efektifitas penggunaan sepeda kampus ITS adalah metode KJ. metode KJ dikembangkan oleh Jiro Kawakita pada tahun 1960an untuk meningkatkan integrasi dan kategorisasi data kualitatif seputar faktor-faktor seperti lingkungan, populasi, hubungan, hierarki dan agama [3]. Menurut Kawakita metode KJ memiliki penerapan universal dan tidak hanya sesuai dengan budaya Jepang dan proses pengambilan keputusan manajemen yang umumnya didasarkan pada model orientasi kelompok. Kawakita berpendapat bahwa sifat manusia itu universal, dan bahwa metode KJ, sebagai alat pengambilan keputusan dapat digunakan di semua masyarakat di seluruh dunia untuk melaksanakan pembangunan sosial dan ekonomi [4].
Metode ini merupakan cara yang efektif dalam mengatur masuknya berbagai ide kreatif dan informasi yang cukup banyak dari beberapa orang dalam sebuah diskusi kelompok. Metode ini dirancang untuk memfokuskan tim untuk menyelesaikan sebuah permasalahan [5]. Metode ini juga biasa disebut Affinity Diagram yang merupakan bagian dari pengkategorian ide.

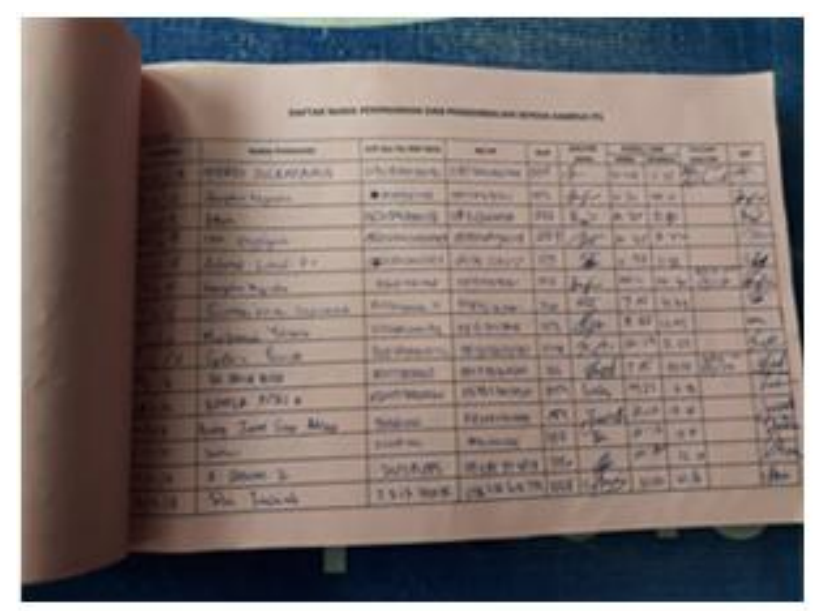

Gambar 7. Data peminjam fasilitas sepeda kampus IT S dari tahun 2013

\section{Tahapan Metode}

1. Tahap pertama adalah menentukan fokus pertanyaan seperti siapa pengguna sepeda kampus?, tujuan peminjaman?, mengapa mahasiswa di ITS kurang memanfaatkan fasilitas sepeda kampus?.

2. Tahap kedua yang dilakukan adalah dengan mengumpulkan beberapa orang berhubungan dengan masalah yang akan dikerucutkan sebagai sampel, orang yang dikumpulkan berjumlah enam orang mahasiswa ITS dari beragam departemen, untuk mendapatkan sudut pandang yang berbeda. Departemen tersebut yaitu, Departemen Desain Komunikasi Visual, Desain Produk, Teknik Perkapalan, Teknik Kimia, Teknik Kelautan, dan Perencanaan Wilayah Kota.

3. Tahap ke tiga, mahasiswa-mahasiswa tersebut menuliskan jawaban dari pertanyaan di atas, alasan tersebut dituliskan di atas sticky notes yang telah disediakan. Metode ini dilakukan dengan diam tanpa berargumen atau diskusi satu sama lain, hanya moderator yang berhak berbicara selama metode ini berlangs ung.

4. Dalam waktu kurang lebih 2 jam, peserta diskusi harus fokus pada hasil jawaban yang ditulis pada sticky notes karena dalam satu sticky notes hanya boleh diisi satu alasan saja. Jawaban yang dituliskan pada sticky notes diharapkan merupakan pengamatan, pengetahuan, serta gagasan.

5. Sticky notes kemudian dikumpulkan di sebuah papan (flipchart) dan dikelompokkan berdasarkan jawabanjawaban yang serupa. Pengelompokkan jawaban pada Sticky notes dapat dilihat pada Gambar 8.

6. Dari pengelompokkan tersebut, didapatkan tiga alasan utama mengapa mahasiswa ITS kurang menggunakan fasilitas sepeda kampus. Gambar 9 menunjukkan 3 kelompok hasil pengkategorian jawaban. 
Teknik KJ menjanjikan perwakilan yang setara, terlepas dari politik dan kepribadian yang terlibat, tidak masalah siapa yang memiliki kekuatan paling besar ataupun siapa yang paling fasih bisa memperdebatkan sudut pandang mereka terhadap masalah. Dengan mengedepankan kerangka kerja di mana setiap orang akan bekerja bersama sebagai sebuah tim (meskipun dengan diam dan tanpa suara), keputus an dibuat secara demokratis, dengan tanpa peluang untuk dipaksa. Tekanan dalam kelompok tidak akan mempengaruhi hasil [6]. Metode ini memungkinkan kelompok diskusi dengan cepat mencapai konsensus tentang prioritas data secara subjektif dan kualitatif [7].

\section{HASIL DAN PEMBAHASAN}

Dari proses penggunaan metode KJ, didapatkan 3 (tiga) alasan utama atas kurangnya minat mahas iswa ITS untuk memanfaatkan fasilitas sepeda kampus yaitu :

1. Tidak mengetahui prosedur peminjaman sepeda kampus ITS

2. Kendala pribadi

3. Lebih memilih alternatif lain yang lebih praktis.

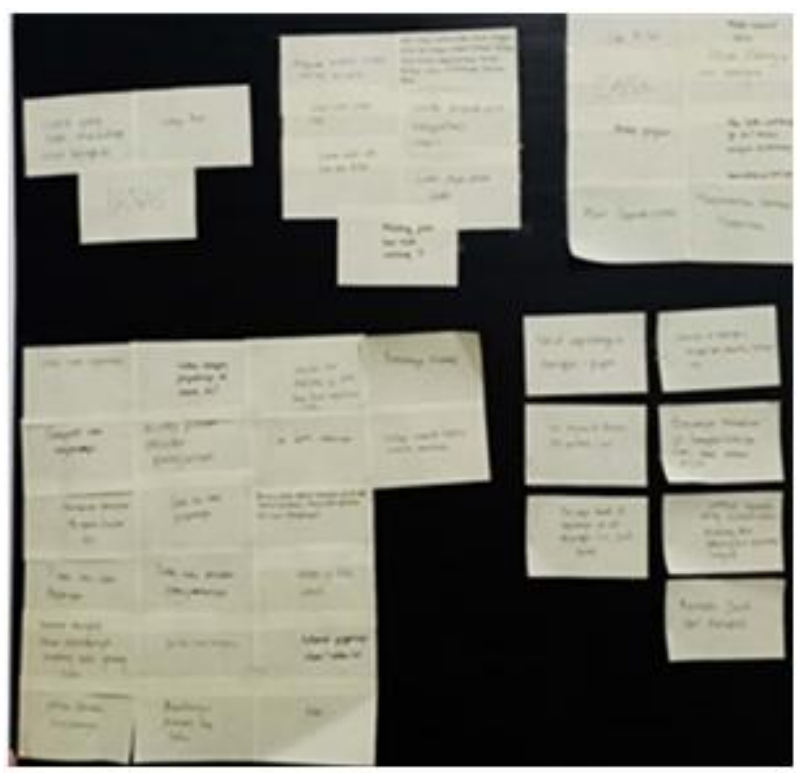

Gambar 8. Papan penempelan sticky notes

Dari ketiga masalah tersebut kemudian dikerucutkan kembali dengan menggunakan sistem voting untuk menentukan satu dari ketiga penemuan masalah. Dari hasil voting, suara terbanyak adalah alasan "tidak tahu prosedur peminjaman sepeda kampus". Hasil voting tersebut disepakati bersama dan dijadikan sebagai masalah dari pertanyaan "Mengapa mahas iswa ITS kurang memanfaatkan fasilitas sepeda kampus ITS?". Sehingga didapatkan permasalahan yang merupakan jawaban dari pertanyaan tersebut yakni "Mahasiswa ITS kurang menggunakan fasilitas sepeda Kampus karena tidak mengetahui prosedur peminjaman sepeda kampus".

Permasalahan tidak mengetahui prosedur peminjaman sepeda kampus inilah yang dirasa menyebabkan keberadaan unit sepeda ini kurang efektif. Tidak menearik minat mahas is wa atau pengunjung ITS lainnya

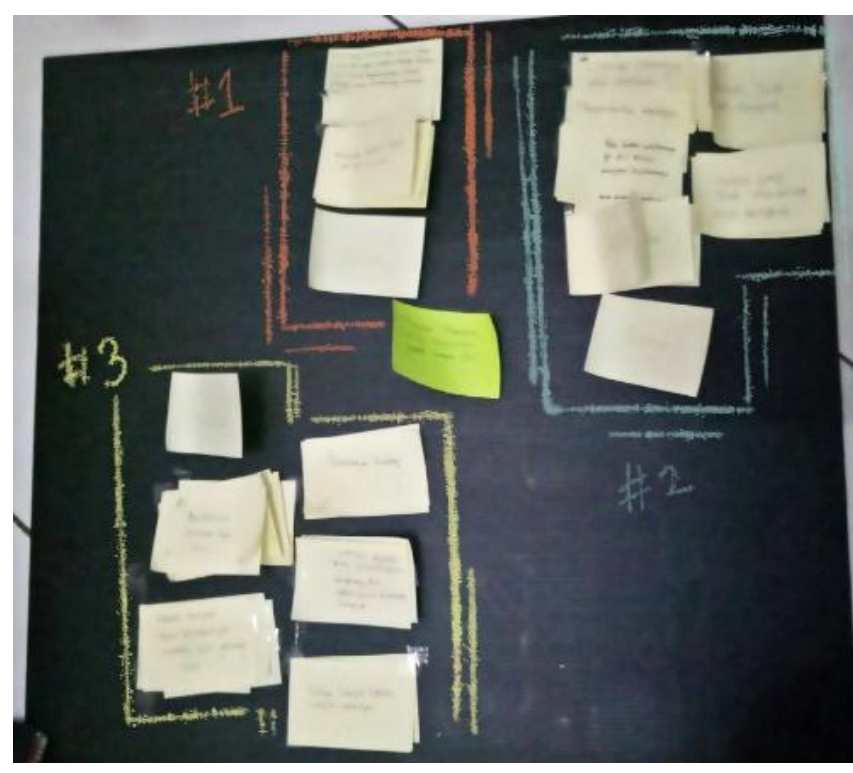

Gambar 9. Hasil penkategorian jawaban

\section{KESIMPULAN/RINGKASAN}

Pada pembahasan ini, metode KJ yang telah dilakukan kepada beberapa sampel yang merupakan mahasiswa ITS dari beberapa Departemen. Hasil yang telah didapatkan dari sticky notes yang telah terkumpul adalah, banyak mahas is wa ITS yang tidak mengetahui prosedur peminjaman sepeda kampus ITS. Terdapat juga kendala pribadi seperti tidak memiliki niat untuk meminjam sepeda, tidak memiliki waktu untuk meminjam karena takut terlambat, atau karena bagi mereka mengendarai sepeda terlalu melelahkan karena cuaca yang juga tidak mendukung. Mahasiswa ITS juga lebih memilih untuk bepergian dengan kendaraan teman atau menggunakan ojek online, karena cara ini dianggap lebih efektif, hal ini menyebabkan efektifitas penggunaan fasilitas sepada kampus menjadi berkurang.

Dari metode ini peneliti mendapatkan berbagai hasil yang kemudian difokuskan menjadi satu permasalahan melalui voting. Dari hasil voting partisipan, didapatkan permasalahan utama bahwa "Mahasiswa ITS tidak mengetahui prosedur peminjaman fasilitas sepeda kampus ITS”. Hal tersebut adalah kendala yang paling banyak ditemui dari semua partisipan yang telah mengisi sticky notes. Hasil voting juga menunjukkan bahwa partisipan sependapat bahwa hal tersebut merupakan kendala utama yang mereka hadapi dalam meminjam fasilitas sepeda kampus ITS ini. Meskipun hasil Teknik KJ bersifat subyektif dan kualitatif, ini adalah cara yang ampuh bagi tim untuk berkumpul, memecahkan masalah, dan memprioritaskan langkah-langkah selanjutnya.

Dari hasil observasi di lapangan, prosedur peminjaman fasilitas sepeda sudah terpasang di Shelter Point peminjaman sepeda ITS yang berada di pintu masuk utama Gerbang ITS, namun secara konten dan visual keterbacaan nya kurang. Gambar 10 mengilustrasikan tata cara atau prosedur peminjaman sepeda kampus ITS dengan informasi yang cukup padat, font dibuat terlalu kecil sehingga tidak terbaca di jarak yang jauh. Desain tidak menarik, sehingga pada saat dipasang, warga ITS tidak sadar kalau banner 
tersebut memberikan informasi tentang alur peminjaman sepeda ITS. Selain itu penempatannya jug kurang strategis. Selain itu banner tersebut sudah dalam kondisi yang kurang baik.

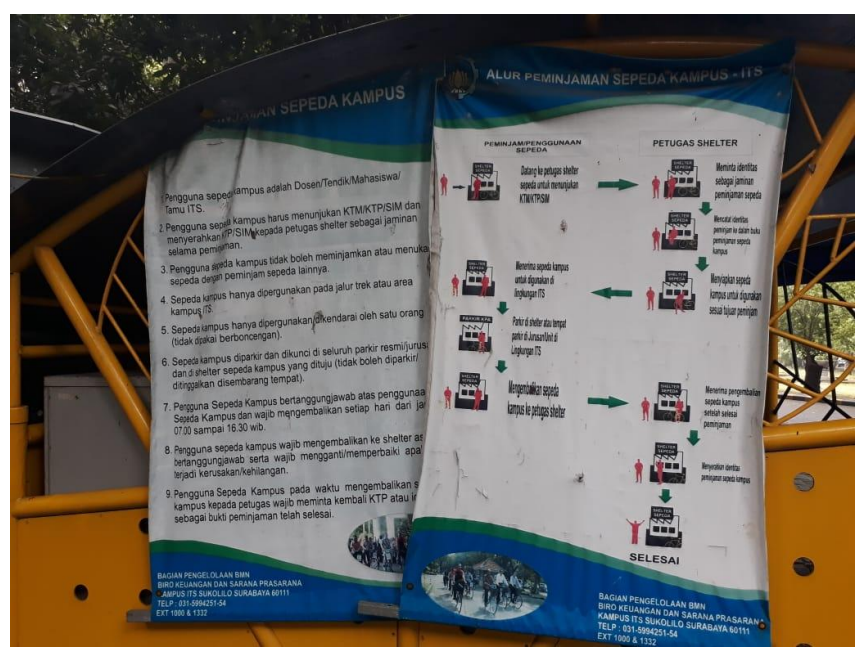

Gambar 10. Informasi alur peminjaman fasilitas sepeda IT S.

Karena program sepeda kampus ini telah berjalan kurang lebih 6 tahun, sebaiknya pengelola memperbaharui informasi tentang prosedur peminjaman fasilitas sepeda kampus, misalkan dengan cara mempromosikan kembali program ini melalui media sosial ITS dengan bahasa yang lebih dekat dengan millennial, mendesain kembali tata cara peminjaman sepeda kampus ITS dan dipasang tidak hanya di shelter sepeda, namun juga ditempat lain di lingkungan kampus, melibatkan sepeda kampus dalam rangkaian acara yang diadakan di lingkungan kampus ITS. Hal ini sangat penting mengingat dari hasil perhitungan lalu lintas, pada satu hari kerja, kendaraan baik motor dan mobil yang keluar masuk ITS hampir mencapai angka 34.000. Banyaknya kendaraan ini berbanding lurus dengan jumlah emisi karbon yang ada di ITS [8]. Hal ini semakin meningkatkan dampak polusi udara akibat kendaraan bermotor di lingkungan kampus ITS.
Sebagai warga ITS, mahasiswa ITS juga memiliki tanggung jawab untuk ikut menjaga lingkungan ITS dan mendukung program yang ada. Dengan ikut menjalankan program ini warga dapat ikut dalam menjaga lingkungan dengan mengurangi polusi yang dikeluarkan oleh kendaraan bermotor. Namun, kendala ketidaktahuan prosedur peminjaman yang kemudian menghambat mahasiswa dalam berpartisipasi dalam program ini. Banyak mahasiswa yang masih kebingungan dalam prosedur peminjaman sepeda kampus ITS. Hal tersebut menyebabkan mereka untuk memilih alternatif lain yang lebih mudah.

Dengan hasil yang didapat dari penelitian tentang pengukuran efektifitas penggunaan sepeda Kampus ITS, diharapkan dapat dapat digunakan sebagai rujukan untuk mengatasi masalah bagi pengembangan sepeda kampus ITS. Sehingga diharapkan nantinya mahasiswa dapat ikut berpartisipasi dalam menjalankan program Eco Campus ITS dengan menumbuhkan kembali budaya bersepeda agar dapat mengurangi dampak polus i udara akibat kendaraan bermotor di lingkungan kampus ITS, sehingga menciptakan udara yang segar dan sehat bagi para civitas akademika ITS.

\section{DAFTAR PUSTAKA}

[1] https://www.its .ac.id/news/2013/04/11/s epeda-kampusits-siap-di-launching/

[2] https://www.its .ac.id/news/2014/10/01/its-teruskembangkan-fasilitas-sepeda-kampus/

[3] DeCarlo, Neil, Samuel, Philip, \& Silverstein, David, “The Innovator's Toolkit", John Wiley \& Sons (2012)

[4] Raymond, Scupin, "The KJ Method: A Technique for Analyzing Data Derived from Japanese Ethnology", Human Organization: Summer 1997, Vol. 56, No. 2, pp. 233-237 (1997)

[5] Martin, B. d., "Universal Methods of Design", US: Rockport Publisher, (2012)

[6] Spool, Jared. "The KJ-Technique: A Group Process for Establishing Priorities", http://www.uie.com 2004

[7] https://articles.uie.com/kj_technique/

[8] https://www.its.ac.id/news/2018/10/12/wujudkan-its smart-eco-campus-lewat-penguran gan-emis i-karbon/ 